\title{
ANÁLISE DA FREQUÊNCIA E PERCEPÇÃO SOBRE VIOLÊNCIA OBSTÉTRICAS E SUAS REPERCUSSÕES ÉTICO-LEGAIS
}

\author{
GUIRALDELLO, Lidiane $^{1}$ \\ LASCALA, Maysa Rocha ${ }^{2}$ \\ GREEN, Marcia Cristina Taveira Pucci ${ }^{3}$
}

RESUMO: A violência obstétrica é qualquer ato ou conduta, realizada por um profissional da saúde, que viole os direitos da mulher durante o parto e que possa causar dano físico, sexual ou emocional. Trata-se de um tema ressonante, uma vez que os movimentos em prol da humanização do parto têm ganhado forças atualmente. OBJETIVO: Identificar a percepção de profissionais da saúde, pacientes e estudantes sobre violência obstétrica, e avaliar o impacto desta na relação médico-paciente. METODOLOGIA: Estudo de caráter transversal, quantitativo e qualitativo. Utilizou-se questionários com o objetivo de identificar a percepção de pacientes, estudantes e profissionais da saúde sobre violência obstétrica. RESULTADOS: Entrevistou-se 158 pessoas (80 pacientes, 46 estudantes, 32 profissionais de saúde). Quanto as pacientes, 49\% considera a violência obstétrica como uma má assistência médica ou atendimento anti-ético, seguida de violência verbal (39\%). Destas, 16\% presenciaram ou vivenciaram episódios de violência. Em relação aos profissionais de saúde, $60 \%$ considera a realização de procedimentos sem indicação como violência. Por fim, os estudantes de medicina consideraram a violência obstétrica como a realização de procedimentos desnecessários durante o trabalho de parto $(71,5 \%)$. CONCLUSÃO: obteve-se opiniões pouco divergentes sobre a percepção da violência obstétrica entre os grupos estudados, diferindo de acordo com os aspectos culturais e socioeconômicos. Contudo, foi concordante o fato de que esse tipo de violência está relacionado, principalmente, com qualquer ato que reflita uma afronta ao direito de escolha da mulher e que priorize práticas que não respeitem a individualidade ou desvalorizem o processo de parturição das mesmas.

Palavras-chave: Obstetrícia. Violência contra a mulher. Sistema único de saúde. Ética

SUMMARY: Obstetric violence is any act or conduct carried out by a health professional that violates the rights of a woman during childbirth and can cause physical, sexual or emotional harm. This is a resonant theme, since movements for the humanization of childbirth have gained momentum today. OBJECTIVE: To identify the perception of health professionals, patients and students about obstetric violence, and evaluate the impact of this on the physician-patient relationship. METHODOLOGY: Cross - sectional, quantitative and qualitative study. Questionnaires were used to identify the perception of patients, students and health professionals about obstetric violence. RESULTS: We interviewed 158 people (80 patients, 46 students, 32 health professionals). Regarding patients, $49 \%$ consider obstetric violence as poor medical care or anti-ethical care, followed by verbal violence $(39 \%)$. Of these, $16 \%$ witnessed or experienced episodes of violence. In relation to health professionals, $60 \%$ consider performing procedures without indication as violence. Finally, medical students considered obstetric violence as unnecessary procedures during labor (71.5\%). CONCLUSION: we obtained slightly divergent opinions about the perception of obstetric violence among the groups studied, differing according to cultural and socioeconomic aspects. However, it was consistent that this type of violence is mainly related to any act that reflects an affront to women's right to choose and prioritize.

Keywords: Obstetrics. Violence against women. Unified health system. Ethics

\section{INTRODUÇÃO}

Segundo a legislação venezuelana, especificada pelo Projeto de Lei n. 7.633, a violência obstétrica seria qualquer ato, conduta ou omissão realizada por um profissional da saúde que viole os direitos

\footnotetext{
${ }_{2}^{1}$ Universidade de Franca - Estudante de Medicina 
humanos da mulher durante o processo de parturição fisiológico e que possa levar ao dano ou sofrimento de ordem física, sexual ou psicológica da mulher. (PEREIRA, 2016; ANDRADE, 2014)

Esse tipo de violência atualmente tem se tornado um fenômeno social em constante expansão, o qual está rotineiramente presente em instituições de saúde de todo o mundo.(PEREIRA, 2016) Situações de abuso, desrespeito, negligência e maus tratos são muitas vezes comuns durante o trabalho de parto e os procedimentos desnecessários e invasivos como episiotomias, restrição ao leito no pré-parto, tricotomia, ocitocina de rotina e ausência de acompanhante, também são queixas recorrentes das gestantes. (CIELLO, 2012)

As discussões sobre o assunto estão se tornando frequentes e isso se deve a um movimento feminista em prol da humanização do parto em que os profissionais da saúde devem reconhecer o âmbito emocional envolvimento naquele momento, que é tão esperado pela gestante, e entender que ela deve ter participação ativa nas escolhas do processo de parto. (SENA, 2017)

Embora esse tipo de violência possa ser vivenciado em qualquer fase da gravidez, é mais comum durante o parto, período em que as gestantes se encontram mais fragilizadas e vulnerável às situações semelhantes. (CIELLO, 2012)

Existem três tipos de VO, segundo o dossiê elaborado pela Rede Parto do Principio da CPMI da Violência contra as mulheres: VO física - surge quando são realizados procedimentos invasivos, sem o consentimento da paciente e não justificadas, quando não se respeita a decisão pela via de parto ou o tempo de evolução do mesmo; VO psíquica - envolve tratamento desumanizado e grosseiro, com ameaças e humilhações, assim como omissões de informações sobre o desenvolvimento do parto; VO sexual qualquer ato que viole a intimidade ou o pudor da paciente. (BRASIL, 2002)

Em termos legais, a Argentina foi o primeiro país da América Latina a reconhecer a violência obstétrica, por meio da lei conhecida como "Ley de Parto Humanizado" de 2004. (SENA, 2017) No Brasil, não foi criada, até o momento, uma lei que reconheça a violência obstétrica como uma violação dos direitos das mulheres, há, porém, o Programa de Humanização no Pré-natal e Nascimento, instituído pelo Ministério da Saúde através da Portaria/GM n.569, de 1/6/2000, o qual visa atender as necessidades de atenção específica à gestante, ao recém-nascido e à mãe no período pós-parto. Infelizmente, essa política ainda não atingiu o país de forma integral. (SENA, 2017)

A humanização do parto é um dever das instituições de saúde em receber a mulher, seu concepto e familiares com respeito, assim como adotar medidas e práticas benéficas e necessárias para o acompanhamento do parto, nascimento e puerpério, evitando, sobretudo, procedimentos intervencionistas que não beneficiam a mulher ou o recém-nascido. Para tanto é fundamental uma conduta ética e humanista por parte das instituições e profissionais da saúde, com o intuito de criar um ambiente acolhedor e uma rotina hospitalar de assistência ao parto que suspenda a atual maneira imposta à mulher, sendo desse modo, leal ao princípio da beneficência(obrigação ética de se maximizar o benefício e minimizar o dano), ou seja, fazer o bem. (SENA, 2017)

\section{MÉTODOS}

Estudo de caráter qualitativo, quantitativo e transversal, baseado na aplicação de questionários, realizada em um hospital público, conveniado ao SUS, de uma cidade no interior do estado de São Paulo. Este estudo foi realizado por estudantes do quinto ano do curso de Medicina da Universidade de Franca, sob supervisão de Docente, durante os anos de 2017 e 2018.

A população do estudo incluiu mulheres, puérperas, cujo parto ocorreu na instituição de saúde do estudo. Foram excluídas da pesquisa mulheres menores de 18 anos ou que não tiveram atendimento 
médico em instituições hospitalares durante o parto (parto domiciliar, em ambulâncias e outros). Foram entrevistados também estudantes, do $5^{\circ}$ e $6^{\circ}$ anos do curso de Medicina, além de profissionais da saúde que trabalham no local.

Os questionários foram aplicados em dias alternados, em local reservado, a fim de evitar interferências de terceiros nas respostas. Foram elaborados questionários para cada grupo: o primeiro tem como objetivo determinar o conhecimento em relação ao tema e se as mulheres (pacientes) abordadas já sofreram algum tipo de violência obstétrica durante a admissão do parto ou em outro período da gestação (ANEXO 1). O segundo questionário (ANEXO 2) aborda a experiência do profissional da saúde (médicos, enfermeiros e técnicos de enfermagem) em relação ao assunto, e um terceiro questionário (ANEXO 3) oferece informações sobre o conhecimento dos estudantes de medicina (matriculados entre o $9^{\circ}$ e $12^{\circ}$ período) sobre a violência e/ou experiência sobre a violência obstétrica. Além disso, para cada participante do estudo foi entregue uma cópia do Termo de Consentimento Livre e Esclarecido (TCLE), que deveria ser lido e assinado pelos mesmos antes de responder o questionário.

Este trabalho foi submetido ao Comitê de Ética da Santa Casa de Misericórdia de Franca e segue as diretrizes e normas de pesquisa envolvendo seres humanos, que são estabelecidas pela resolução 466/2012. O protocolo de autorização para a pesquisa pelo comitê de ética segue com o número 79604417.0.0000.5438. O responsável pelo hospital assim como o responsável pela unidade de ginecologia e obstetrícia foram devidamente informados e estando cientes autorizaram a pesquisa.

Os dados dos questionários foram protegidos pelo sigilo e os entrevistados foram identificados em um banco de dados por números, garantindo assim o anonimato. Os questionários foram manuseados por três pesquisadores e os dados inseridos em um único computador. A fim de evitar o risco das informações colhidas vazarem, todos os cuidados necessários para evitar a exposição e resguardá-los foram tomados.

As distribuições de frequências porcentuais das respostas apresentadas pelos três grupos experimentais constituídos por parturientes, profissionais da saúde e estudantes do Curso de Medicina foram representadas em tabelas e gráficos confeccionados no Excel.

A associação entre a avaliação feita pelas pacientes com o período do dia em que o parto foi realizado e com o tipo de parto foi avaliada pela estatística de Qui Quadrado $\left(\chi^{2}\right)$ e a correlação entre a avaliação do parto e a idade e o grau de escolaridade das pacientes foi medida pelo coeficiente de correlação de Spearman, em virtude da não normalidade das populações de origem, avaliadas pelo teste de normalidade de D'Agostino e Pearson.

Nos testes de significância estatística o nível de significância pré-estabelecido foi de 5,0\% $(\alpha=0,005)$ e os mesmos foram realizados no software GraphPad Prism 5.0.

\section{RESULTADOS}

A percepção sobre violência obstétrica - pelos profissionais de saúde, estudantes e pacientes - foi analisada durante o período de Março à Maio de 2018. As informações foram coletadas na Santa Casa de Misericórdia da cidade de Franca, interior do Estado de São Paulo. Também foram analisadas a frequência e o tipo de violência relatada pelos participantes, assim como suas repercussões na relação médicopaciente.

Foram abordadas 158 (cento e cinquenta e oito) pessoas, das quais 4 (quatro) foram excluídas por terem menos de 18 anos de idade (critério de exclusão previamente estabelecido). O restante da amostra foi composto por 46 (quarenta e seis) estudantes de Medicina, 32 (trinta e dois) profissionais da saúde e 76 (setenta e seis) pacientes. 


\section{Profissionais da saúde}

Todos os profissionais da saúde abordados trabalhavam no local de estudo, sendo $57 \%$ destes ( $\mathrm{x}=$ 18) médicos das especialidades de Ginecologia e Obstetrícia e Pediatria; 6\% ( $x=2)$ eram enfermeiros e $38 \%(\mathrm{x}=12)$ técnicos de enfermagem. Em relação à faixa etária, a maioria se encontrava na faixa etária acima dos 40 anos (31\%); $28 \%$ entre 26 e 30 anos; $25 \%$ entre 18 e 25 anos; e o restante na faixa etária de 31 a 40 anos. Dos profissionais, 58\% consideram suas condições de trabalho boas; 38\% regular e 9\% muito boa (Gráfico 1).

Gráfico 1- Percepção das condições de trabalho pelos profissionais da saúde.

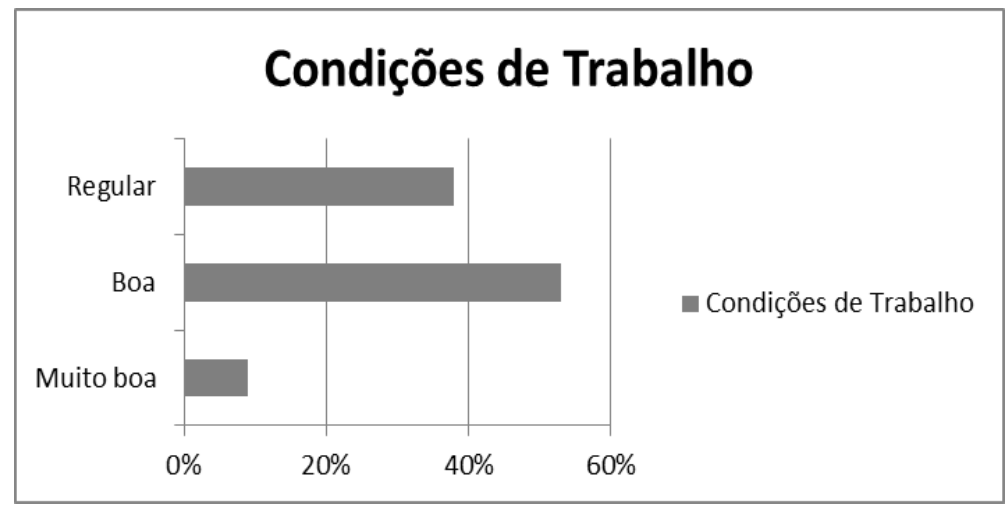

Fonte: Elaborado pelos Autores

Quando questionados sobre o pior período de rendimento, 66\% $(\mathrm{x}=21)$ consideram o período da noite, plantão e pós-plantão como de pior rendimento, $31 \%$ acreditam não haver diferenças, independente do horário de trabalho; os $3 \%$ restantes não responderam. Nenhum dos entrevistados considerou os períodos da manhã ou tarde.

Sobre o que é considerado violência obstétrica, $47 \%$ dos profissionais acreditam ser agressão verbal; $44 \%$ procedimentos sem necessidade e/ou indicação; $25 \%$ agressão física; $22 \%$ agressão psicológica; $22 \%$ falta de autonomia. Outros menos citados foram: procedimentos sem anestesia, falta de explicações sobre procedimentos e/ou condutas, falta de ética. Vale ressaltar que $6 \%$ desconhecem o assunto ou não responderam (Gráfico 2). Além disso, cada entrevistado pode citar mais de um exemplo de violência obstétrica, sendo por essa razão os resultados em porcentagem divergentes na soma final.

Gráfico 2 - Percepção sobre violência obstétrica pelos profissionais da saúde.



Fonte: Elaborado pelos Autores 
Dos 32 profissionais da saúde, aproximadamente 40,5\% dizem já ter presenciado alguma forma de violência obstétrica, sendo que aproximadamente $46 \%$ observaram algum tipo de violência verbal; $31 \%$ procedimentos sem necessidade e/ou indicação; 7,5\% agrupam situações em que houve perda de autonomia da paciente; 7,5\% agressão psicológica (Gráfico 3).

"É o ato de não respeitar a naturalidade do parto, ofender gestante/familiares, procedimentos não indicados. Ou qualquer coisa que ofenda esse momento especial do parto." (Médico)

"Considero violência obstétrica a forma verbal de muitos profissionais, ex: "Na hora de fazer não reclamou", "vc não da conta de parto normal".” (Técnica de enfermagem)

"A falta de respeito e educação de ambas as partes, tanto por profissionais perante ao paciente, quanto paciente perante o profissional." (Enfermeira)

Gráfico 3 - Formas de Violência obstétrica presenciadas por profissionais da saúde.

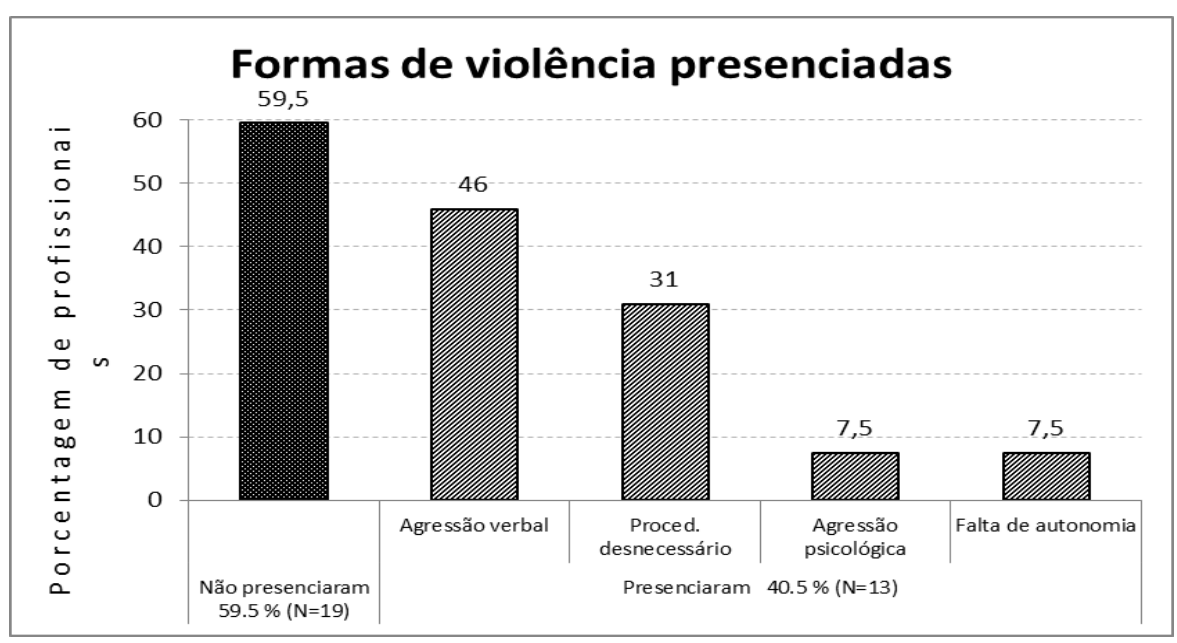

Fonte: Elaborado pelos Autores

Sobre as condutas realizadas rotineiramente no centro obstétrico, 37,5\% ( $\mathrm{x}=12)$ dos profissionais considera algum procedimento como forma de violência. Foram citados: Kristeller (33,5\%), jejum prolongado $(16,5)$, episiotomia $(16,5 \%)$, cesárea sem indicação $(8,5 \%)$, exposição do corpo da mulher $(8,5 \%)$ e dilatação manual do colo $(8,5 \%)$. Novamente, cada entrevistado pode citar mais de um exemplo de condutas (Gráfico 4).

Gráfico 4 - Procedimentos considerados como violência obstétrica pelos profissionais da saúde

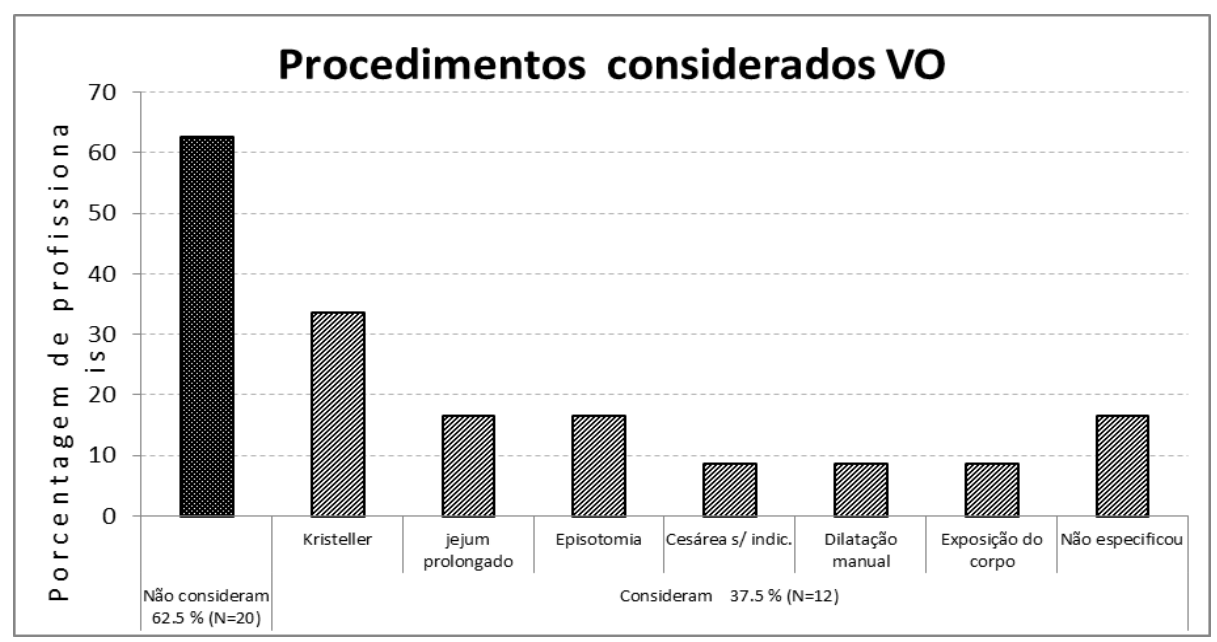

Fonte: Elaborado pelos Autores 


\section{Estudantes}

Todos os estudantes abordados estavam matriculados na mesma Universidade, e pertenciam ao internato. Destes, 76\% tinham entre 18 e 25 anos; 22\% entre 26 e 30 anos; $2 \%$ entre 31 e 40; nenhum tinha mais de 40 anos. Dos 46 alunos, $80,5 \%$ pertencia ao $5^{\circ}$ ano, e os $19,5 \%$ restantes, pertenciam ao $6^{\circ}$ ano.

Quando perguntados sobre o que consideram como violência obstétrica, $48 \%$ definem como a realização de procedimentos sem necessidade e/ou indicação; $22 \%$ falta de autonomia da paciente para escolhas de procedimentos e via de parto; $22 \%$ falta de ética; $17,5 \%$ agressão psicológica; $15 \%$ agressão física; 4,5\% agressão verbal (Gráfico 5).

Gráfico 5 - Percepção sobre violência obstétrica pelos estudantes de Medicina.

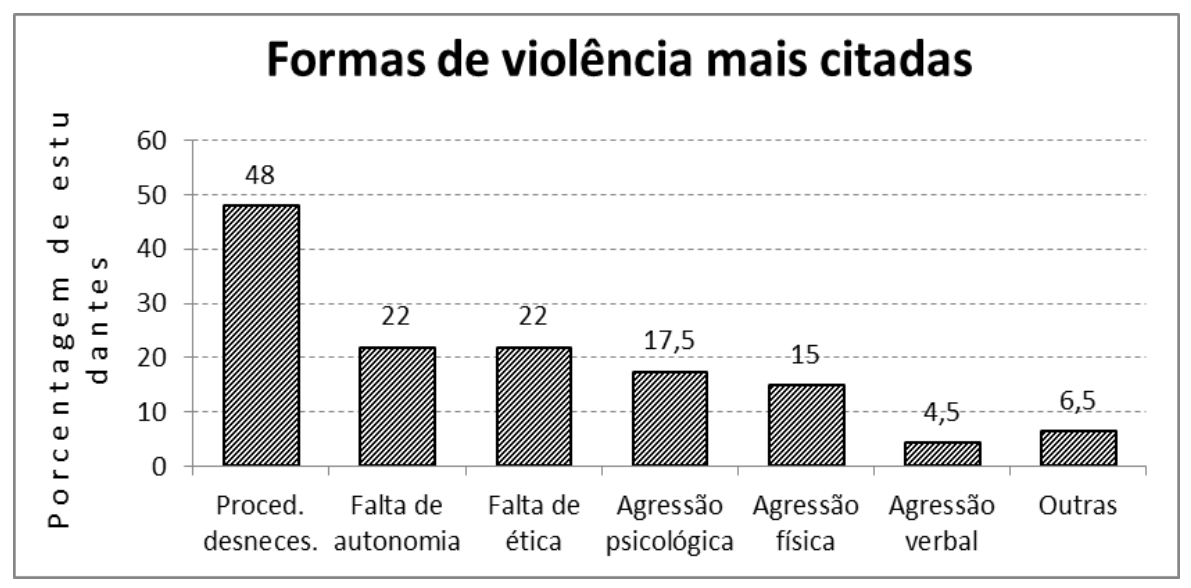

Fonte: Elaborado pelos Autores

Dos 46 estudantes de Medicina, 37\% (x=17) referem já ter presenciado algum episódio de violência obstétrica. A maioria presenciou procedimentos desnecessários $(82,5 \%) ; 17,5 \%$ falta de autonomia; $17,5 \%$ violência verbal; $12 \%$ agressão psicológica. Somente um aluno não respondeu esta questão (Gráfico 6).

“Ato desnecessário que fira fisicamente ou o pudor da gestante." (Estudante do $5^{\circ}$ ano)

"Algo que é feito contra a vontade da gestante, desdenho pela sua situação." (Estudante do $6^{\circ}$ ano)

"Falta de respeito e privacidade com a paciente". (Estudante do $5^{\circ}$ ano)

Gráfico 6 - Formas de Violência obstétrica presenciadas por estudantes de medicina.

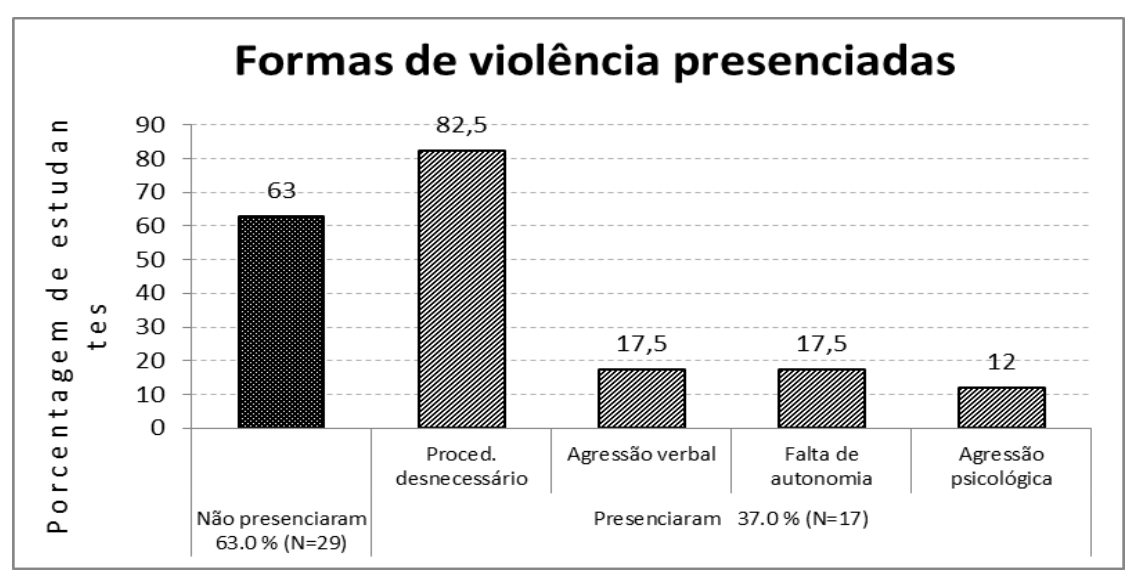

Fonte: Elaborado pelos Autores 
Sobre procedimentos que são realizados diariamente no centro obstétrico, $43,5 \%$ consideram alguma conduta como forma de violência. $40 \%$ desses alunos consideram cesárea sem indicação clínica como forma de violência obstétrica; $25 \%$ Kristeller; $20 \%$ fórceps sem indicação; 20\% episiotomia e 15\% a rotura artificial de bolsa amniótica (Gráfico 7).

Gráfico 7 - Procedimentos considerados como violência obstétrica pelos estudantes de medicina.

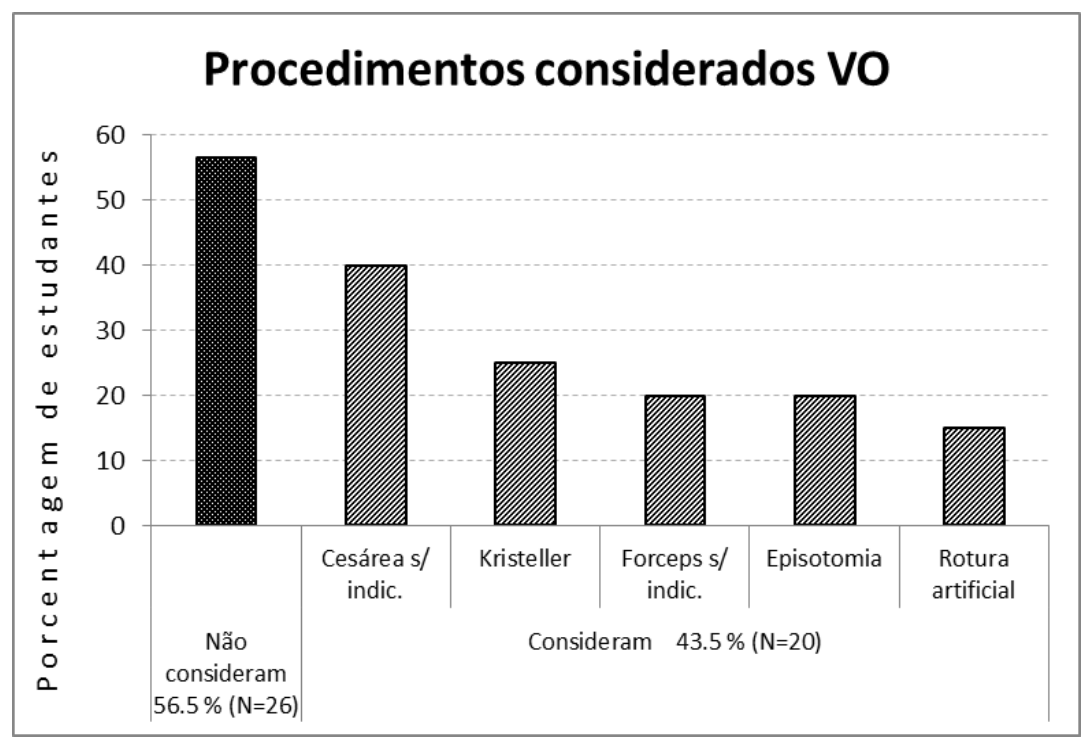

Fonte: Elaborado pelos Autores

\section{Pacientes}

Foram entrevistadas 80 pacientes, das quais $4(5 \%)$ eram menores de 18 anos, sendo, portanto, excluídas do estudo. Das 76 pacientes restantes, $42 \%$ tem entre 18 e 25 anos; $30 \%$ entre 31 e 40 anos; $24 \%$ entre 26 e 30 anos; $3 \%$ tem mais de 40 anos. Uma única paciente não respondeu sua idade (1\%).

A respeito da escolaridade, a maioria possui Ensino Médio completo ou incompleto ( $72 \%$ - $x=55$ ), $16 \%$ Ensino Fundamental completo ou incompleto e $9 \%$ Ensino Superior. Em relação à via de parto, $71 \%$ foram cesárea e o restante parto normal (29\%). Nenhum parto fórceps, natural, domiciliar, humanizado ou em trânsito foi mencionado. Vale ressaltar, o predomínio de parto cesárea em mulheres de escolaridade até o ensino médio (completo ou não), correspondendo à $78 \%$ destas e $56 \%$ de todas a gestantes. Das mulheres que estudaram até o Ensino Fundamental, 58\% destas realizaram cesárea. Já em relação as mulheres que cursaram até o Ensino superior $56 \%$ realizaram parto por via vaginal.

Quando questionados sobre o atendimento, 43\% consideram classificaram como "muito bom"; $39 \%$ como "bom"; $16 \%$ como "regular"; $2 \%$ como "ruim". O item "péssimo" não foi mencionado. A partir desses dados foi possível estabelecer uma correlação positiva com a idade e avaliação do atendimento, sendo que quanto maior a idade das pacientes entrevistadas, melhor a avaliação quanto ao atendimento prestado na instituição da pesquisa. Significância positiva, sendo r=0,28 e p=0,0113.

Outra relação bem estabelecida é a avaliação do atendimento com o período no qual o parto foi realizado, sendo na maioria dos casos considerado como um atendimento muito bom, os partos realizados no período da manhã; bom os realizados no período da tarde e regular os realizados nos períodos noturnos e de plantão. Quiquadrado: $x^{2}=14,52 ; p=0,024$ (Gráfico 8). 
Gráfico 8 - Avaliação do serviço prestado durante o trabalho de parto e parto avaliados por período do dia.

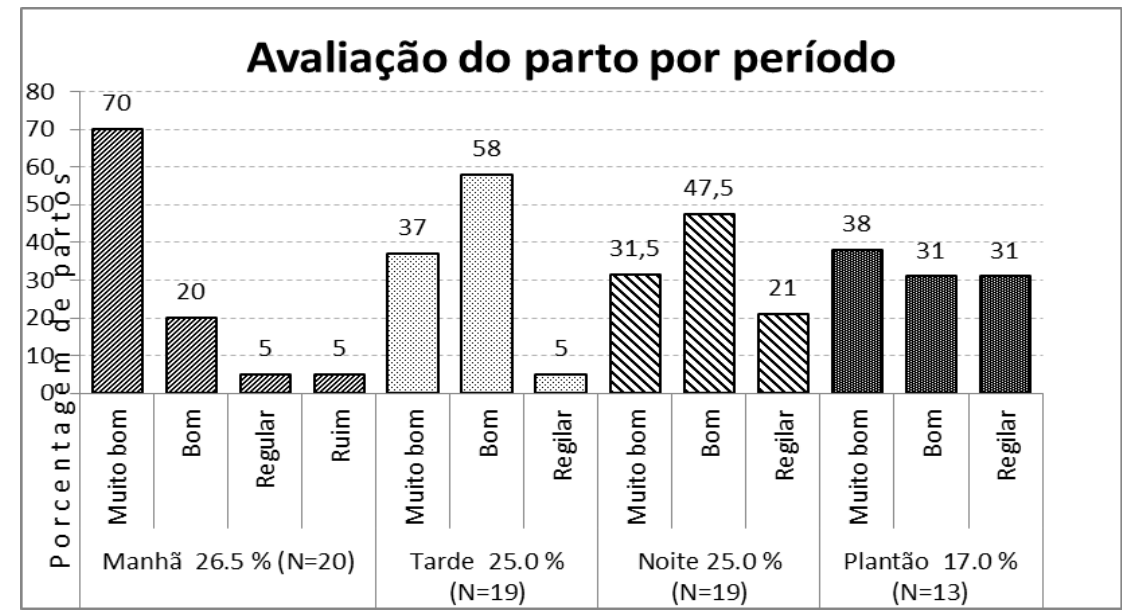

Fonte: Elaborado pelos Autores

Foi percebido ainda, que a qualidade do atendimento independe do tipo de parto. $X^{2}=0,51$; p=0,7756 (Gráfico 9).

Gráfico 9 - Avaliação do serviço prestado durante o trabalho de parto e parto e sua relação com a via de parto.

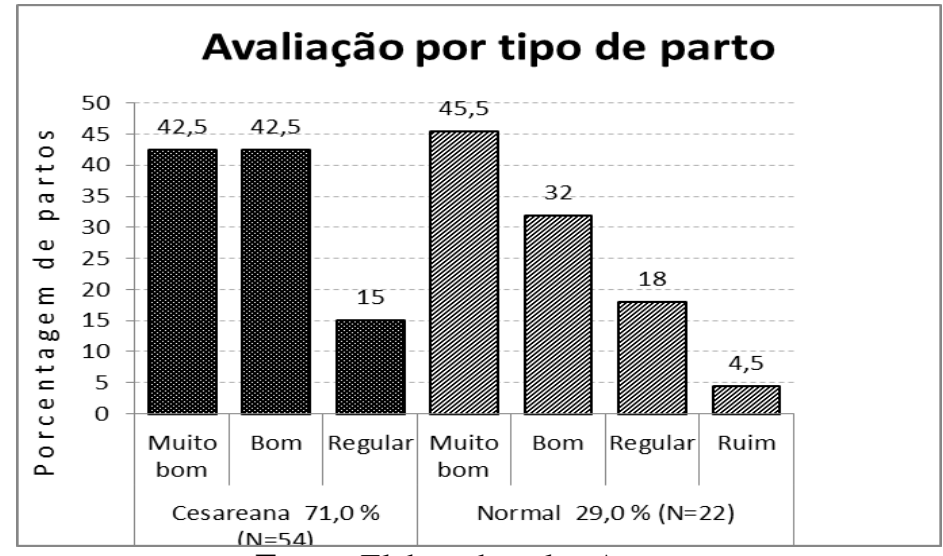

Fonte: Elaborado pelos Autores

Além disso, 22,5\% ( $\mathrm{x}=17)$ afirmaram ter faltado algo durante o atendimento, sendo mencionado por 59\% falta de atenção dos profissionais; $23,5 \%$ falta de medicamentos ou materiais (Gráfico 10).

Gráfico 10 - Percepção das pacientes sobre as carências durante o atendimento.



Fonte: Elaborado pelos Autores 
Quando indagadas sobre o que consideravam como violência obstétrica, 18,5\% acreditam ser violência verbal; $17 \%$ desrespeito; $16 \%$ falta de autonomia; $10,5 \%$ falta de ética; $8 \%$ falta de empatia; 5,5\% procedimentos sem necessidade (Gráfico 11 ).

Gráfico 11 - Percepção das pacientes sobre violência obstétrica.



Fonte: Elaborado pelos Autores

Das 76 pacientes, $15,8 \%(x=12)$ já vivenciaram um caso de violência obstétrica, seja nesta ou em outra internação. Destas pacientes, $41 \%$ vivenciaram má assistência médica; $41 \%$ falta ética; $9 \%$ relata agressão verbal; $9 \%$ procedimentos desnecessários (Gráfico 12). Destas pacientes que relatam violência, a maioria tem entre 18 e 25 anos (50\%), seguidos de mulheres entre 31 e 40 anos (33\%) e mulheres entres 26 e 30 anos (17\%). Além disso, os casos foram mais observados em mulheres de escolaridade até o ensino médio (83\%), sendo ensino fundamental e superior responsável cada um por cerca de $8 \%$. Os casos também estiveram mais presentes nos casos de parto cesárea $(75 \%)$ e partos ocorridos no período da tarde (50\%), enquanto que nos períodos noturnos/plantão esteve presente em $42 \%$.

"É quando vc é tratada com falta de respeito pelos profissionais. Eles acha que são melhores do que os paciente." (Paciente)

"Assuntos desagradáveis na hora da cirurgia". (Paciente)

"O jeito de tratar as pacientes, ou talvez o tempo que os médicos nos deixam sofrendo antes do parto, e também o tempo que demoramos para conseguir ir para o quarto depois que temos nossos bebês..." (Paciente)

“(...) algumas enfermeiras educadas outras não, umas faz por amor outras por amor ao dinheiro." (Paciente)

Gráfico 12- Casos de Violência Obstétrica vivenciada pelas pacientes.

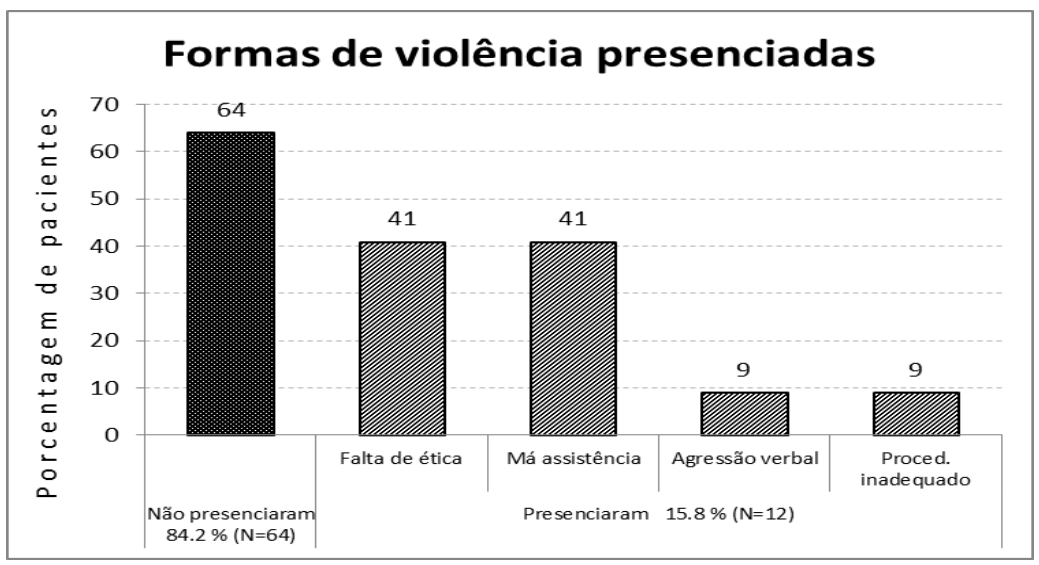

Fonte: Elaborado pelos Autores 
Me internei as $22 \mathrm{~h}$ do dia 22/03/18 mas cheguei aqui por volta das $19 \mathrm{~h}$ senti muitas dores a noite toda e após tomar um remédio no soro passou 20 minutos eu ganhei meu bebê. Não sou médica e não sei os procedimentos, mas esta injeção podia ser aplicada antes, me parece que não tinha vagas na recuperação e nos quartos acho que por isso não tomaram certos procedimentos antes. (Paciente)

"No meu parto por ser prematuro um medico disse que não iria passar nada para enduzir o parto sendo que já estava tendo mtas contrações, fiquei mais da metade do parto sem nada, achei que isso foi muito sem respeito porque nem todos dilatam facilmente." (Paciente)

"Meu filho estava já com a cabeça apontada para nascer, eu pedi p/uma estagiária que estava no pré-parto chamar o médico pra mim, ela me respondeu que não precisava de me examinar porque ela tinha acabado de olhar e o meu bebê ia demorar um pouco pra nascer, quando ela viu que eu estava dizendo a verdade me pois em uma cadeira de rodas, com o bebê já nascendo e me levou pra sala de parto...” (Paciente)

"Fui forçada a ficar mais de 12 horas em uma tentativa frustrada de indução ao parto normal, com 41 semanas de gestação, na minha primeira gestação.” (Paciente)

"Não gostei do aprendiz ficar tocando a gente toda hora" (Paciente)

\section{DISCUSSÃO}

A violência, considerada atualmente como um problema de saúde pública, é de difícil definição, por sua alta complexidade e entendimento, como apontam alguns autores. Minayo e Souza (1998) a definem como qualquer ação intencional que cause algum tipo de dano a um indivíduo, seja esse dano físico, psicológico, social e/ou espiritual; Santos (1996) a considera como um ato de coerção, real ou virtual, que impeçam o reconhecimento do outro. A Organização Mundial da Saúde (OMS) define violência como qualquer ato intencional de força ou poder que resulte ou possa resultar em dano físico, psicológico, privação ou deficiência de desenvolvimento. Em vista disso, algumas condutas, realizadas rotineiramente nos centros obstétricos, passaram a ser consideradas como violência, sendo enquadrada na terminologia "Violência Obstétrica" (VO). (COELHO, 2014; PEREIRA, 2016)

$\mathrm{O}$ abuso físico compreende práticas não justificáveis clinicamente e procedimentos didáticos que desrespeitam a dor da paciente com o argumento inconsistente do parto já ser um processo doloroso e por isso, esses atos não fariam diferença significativa para a parturiente. Dentre esses procedimentos podemos exemplificar os toques vaginais sucessivos, cesáreas e episiotomias desnecessárias. Já o abuso verbal e o cuidado indigno seriam a forma desrespeitosa de tratamento e comunicação que leva a ridicularização da dor sentida no trabalho de parto. (TESSER,2015; BOWSER, 2010)

O cuidado não confidencial ou privativo, ou violência sexual, estaria inserido em um cenário comum nas maternidades públicas, as quais mantêm enfermarias obstétricas coletivas e submetem as mulheres a expor suas intimidades em salas muitas vezes sem biombos que separam os leitos. (CIELLO, 2012; TESSER, 2015; BOWSER, 2010)

A imposição de intervenções não consentidas ou mesmo, intervenções aceitas com base em informações parciais ou distorcidas revela que muitas vezes, episiotomias e planos de parto são feitos sem a devida autorização da paciente, assim como, alguns procedimentos são realizados sem uma justificativa ou indicação plausível, ou mesmo por motivos duvidosos como, por exemplo, a indução ao parto cesárea em virtude de um "pós-datismo de 40 semanas", por circular de cordão ou para "prevenir danos sexuais na mulher”. (TESSER,2015; BOWSER, 2010)

Há ainda, o ato de discriminar a mulher, com o tratamento diferente e menor cuidado baseando-se em certos atributos considerados negativos como pacientes pobres, não escolarizadas, mais jovens, negras, as que questionam ordens médicas, ou são consideradas muito queixosas, descompensadas ou 
demandantes. Isso pode levar ao abandono ou recusa da assistência, pois essas mulheres são frequentemente deixadas por último no atendimento, o que implica em riscos importantes à sua segurança física. (TESSER,2015; BOWSER, 2010)

O objetivo desse trabalho foi determinar a percepção de cada grupo abordado (estudantes, profissionais da saúde e pacientes) sobre o assunto. Dessa forma, foi possível determinar que cada grupo possui opiniões divergentes sobre o assunto, que correspondem as suas experiências de vida. Como exposto anteriormente em resultados, a maioria dos profissionais da saúde consideram violência obstétrica: agressão verbal, realização de procedimentos desnecessários e agressão física.

Resultado semelhante foi observado pelos estudantes de Medicina, em que a maioria também acredita ser a realização de procedimentos desnecessários, sendo destacado por esse grupo a falta de autonomia e empatia e/ou ética por parte do profissional que conduz o parto.

Já as pacientes, definiram violência obstétrica como uma assistência médica de baixa qualidade ou anti-ética, agressão verbal e falta de autonomia.

Apesar de ser considerado tema recente, o assunto é abordado há muitos anos. Já no final da década de 1950, o jornal americano para donas de casa, Ladies Home Journal, publicou uma matéria intitulada "Crueldade nas Maternidades", em que o tratamento das gestantes era descrito como tortura. Na mesma época, no Reino Unido, foi criada a Sociedade para Prevenção da Crueldade contra as Grávidas, sendo a carta de convocação publicada no jornal The Guardian: (DINIZ, 2015)

"Nos hospitais, as mulheres têm que enfrentar a solidão, a falta de simpatia, a falta de privacidade, a falta de consideração, a comida ruim, o reduzido horário da visita, a insensibilidade, a ignorância, a privação de sono, a impossibilidade de descansar, a falta de acesso ao bebê, rotinas estupidamente rígidas, grosseria [...] as maternidades são muitas vezes lugares infelizes, com as memórias de experiências infelizes." (1960 apud BEECH; WILLINGTON, p. 2)

Abordagens feministas feitas por Adrienne Rich e edições do clássico Ourbodies, Ourselves, assim como outros livros feministas publicados entre os anos de 1950 e 1980 contribuíram para denunciar as más práticas nas maternidades e inspirar mudanças na área. (DINIZ, 2015)

No Brasil, desde a década de 1980 o tema já era abordado em trabalhos feministas como Espelho de Vênus (Grupo Ceres), e foi tema no final da mesma década do Programa de Atenção Integral à Saúde da Mulher (PAISM). Porém, apesar de estar sendo discutido, mantinha-se negligenciado, e por essa razão tem-se a ideia errônea de que o assunto é recente em discussões e estudos. (DINIZ, 2015)

Atualmente, o Código de Ética Médica permite que os profissionais sejam penalizados desde advertências até perda do direito de exercer a medicina, desde que a violação seja comprovada por perícia ou testemunhos. (PEREIRA, 2016; BRASIL, 2002; COELHO, 2014; ZANARDO, 2017) O plano de inserir um sistema de humanização no parto e nascimento vem se configurando como uma opção coerente para coibir essas questões relacionadas à violência nos centros obstétricos, sendo essa política, uma ferramenta com grandes possibilidades de transformação do modelo que domina a assistência ao parto na atualidade. (PEREIRA, 2016; BRASIL, 2002; COELHO, 2014; ZANARDO, 2017)

Essa transição vem sendo sugerida por vários órgãos, dentre eles, pela Organização Mundial da Saúde (OMS), e no Brasil, pelo Ministério da Saúde, os quais propõe um cuidado às parturientes que retome as bases do parto natural. Isso inclui a atuação de uma equipe qualificada e multiprofissional que assista a mulher não só durante o parto, mas também por toda a gestação e torne esse evento na vida da gestante como um processo natural e humanizado. (NARCHI, 2013)

O parto e o nascimento humanizado relacionam-se a necessidade de uma nova compreensão desse processo como uma experiência efetivamente humana, de forma que, ter empatia, acolher, ouvir, orientar e criar vínculos com a mulher são atitudes fundamentais. Para tanto, faz-se necessário também, a criação de 
um cenário acolhedor no qual predomine práticas que acabem com o tradicional isolamento imposto à mulher no processo do parto. Respeitar a individualidade e valorizar a parturiente dignifica a tríade mulher, recém-nascido e família, baseando-se em condutas éticas e solidárias. (BRASIL, 2002; KOETTKER, 2013)

Episiotomia, manobra de Kristeller, uso de ocitocina, cesárea sem consentimento ou sem indicação clínica, gritos e grosserias, abandono da paciente na sala de pré-parto são atitudes concordantes entre os participantes deste presente estudo e dados encontrados na literatura que aborda assuntos sobre a violência obstétrica.

O número excessivo de cesáreas também é considerado violência obstétrica. Segundo a OMS, taxas superiores a 15\% de cesáreas na população não estão associadas à redução da mortalidade materna e neonatal, devendo, portanto seu uso estar restrito aos casos complicados em que não há a possibilidade de manter o parto biológico. Além disso, foi observado uma prevalência de cesárea em regiões mais desenvolvidas, com pacientes de escolaridade elevada e baixo risco gestacional. (COELHO, 2014; ZANARDO, 2017)

Os achados do trabalho a respeito da incidência de cesárea contradizem a literatura, uma vez que os dados obtidos demonstraram uma prevalência maior de cesárea em pacientes que cursaram até o Ensino Médio, enquanto que as que tinham ensino superior tiveram incidência maior de parto vaginal. Dessa forma, se considerarmos a literatura, ao considerar cesáreas excessivas como $\mathrm{VO}$, as mulheres de escolaridade mais baixa sofreram mais violência do que as de escolaridade mais alta.

Estudos sugerem que mulheres de classes socioeconômicos menos favorecidas, negras, profissionais do sexo, moradoras de rua e adolescentes estão mais sujeitas a omissões e violências por parte dos profissionais da saúde. Esse fato corrobora o encontrado pelo presente estudo, em que os casos de VO relatados pelas pacientes ocorrem na sua maioria em mulheres de escolaridade mediana (Ensino Médio), entre 18 e 25 anos e via de parto cesárea. (DINIZ, 2015)

Importante salientar, que a violência obstétrica tem relação indireta com a morbimortalidade materna, uma vez que alguns procedimentos predispõem o manejo agressivo do parto vaginal, predispondo a complicações obstétricas. Além disto, há a imposição da cesárea como via de escolha. Isso ocorre de forma direta e indireta. Direta, porque as mulheres nem sempre tem o direito de escolha sobre sua via de parto, e indireta porque as más práticas na maternidade fazem com que as mulheres acreditem que parto biológico seja sinônimo de "dor" e "sofrimento", sendo por isso causa de recusa. Há também o abandono de pacientes no momento de sofrimento, sendo estas taxadas de "dramáticas", "escandalosas", entre outros termos. A demora em atender estas pacientes também está associado à aumento da morbimortalidade. (DINIZ, 2015)

A formação dos profissionais de saúde, principalmente dos médicos, tem papel fundamental no que diz respeito ao tratamento e acolhimento dessas gestantes. Contudo a prática médica é inúmeras vezes ensinada de forma desarticulada dos seus princípios éticos, priorizando o ensinamento de competências em detrimento de valores como o cuidado e assistência ao paciente. Há situações nas quais as gestantes são colocadas como objetos de treinamento para internos e residentes, como para a realização de procedimentos como o toque vaginal, a episiotomia, o fórceps ou até mesmo cesarianas sem que essas consintam com esse exercício. Tal atividade está exemplificada nas definições de violência no parto, e também são percebidas pelas mulheres, como demonstrado nos resultados. (DINIZ, 2015)

O ensino de obstetrícia no Brasil, tipicamente, que o estudante de medicina ou médico residente realize um determinado número de procedimentos para que seja avaliado. Em outros países, procedimentos mais invasivos como a episiotomia e o fórceps, são preferencialmente treinados em peças sintéticas, de modo que, no Brasil, muitos profissionais relatam começar seu treinamento das habilidades 
cirúrgicas nas pacientes, comumente em parturientes do SUS. Diversos trabalhos mostram a cultura disseminada do ensino do uso não consentido dos órgãos genitais das gestantes pelos alunos de medicina e outras profissões com intuito de treinamento de habilidades. (DINIZ, 2001)

Essa prática é tão habitual que os profissionais preceptores consideram as pacientes como uma espécie de material didático para o aprendizado do futuro médico. Desse modo, a perpetuação de atos e posturas dos profissionais atuantes funciona como mecanismo de propagação da violência obstétrica; o atentado aos direitos humanos e reprodutivos das mulheres são mantidos como parte de rotinas hospitalares e sequer causam aversão. (DINIZ, 2015; GUIMARÃES, 2017)

Outra questão relevante pesquisada no presente estudo diz respeito às condições de trabalho nas quais os profissionais da saúde estão inseridos. Embora a maioria dos entrevistados tenham considerado tais condições como boas, é importante destacar que grande parte dos profissionais relataram um pior rendimento em suas atividades em períodos prolongados de trabalho (pós-plantão). A partir dessa informação, é possível afirmar que a jornada de trabalho prolongada interfere na qualidade dos serviços prestados, o que pode contribuir para ações, por vezes, não intencionais, que desagradam as gestantes e são consideras como um tipo de violência obstétrica.

As longas jornadas de trabalho enfrentadas por médicos e enfermeiros estão associadas, sobretudo a baixa remuneração desses profissionais. Esse fato motiva estes trabalhadores a se submeterem a uma sobreposição de vínculos trabalhistas, ou seja, em períodos nos quais deveriam descansar, se responsabilizam de outros encargos ou realizam muitas horas extras. As instituições de saúde, por sua vez, mostram-se cúmplices de tal prática, de modo que há uma carência significativa de mão de obra na área da saúde publica em muitas regiões brasileiras. (SILVA, 2012)

Há uma relação intrínseca entre a jornada de trabalho e o estresse. Isso pode desencadear exaustão emocional, despersonalização e diminuição do envolvimento pessoal no trabalho do profissional da saúde, sendo assim, um fator contribuinte para atitudes que diminuem a qualidade do serviço prestado, assim como a não valorização do cuidado continuo com a paciente. Desta forma surge a assistência médica de baixa qualidade e a falta de empatia, itens muito considerados entre as pacientes escutadas por este estudo. (SILVA, 2012; HOELZS, 2015)

Ao analisar os casos de $\mathrm{VO}$ expostos pelas pacientes, podemos afirmar que o grande desafio seja o atendimento individualizado. Como foi exposto em resultados, algumas pacientes gostariam do uso da ocitocina precocemente por exemplo, ou seja, embora a prática seja considerada por muitos autores como forma de violência, a paciente aguardava a conduta como uma forma de beneficio no seu caso, sendo, portanto o não uso considerado VO. Portanto, o diálogo com a paciente é de suma importância no transcorrer do trabalho de parto, para que desta forma, suas necessidades sejam atendidas plenamente e de forma satisfatória.

\section{CONCLUSÃO}

O interesse em realizar estudo se deu em função de tentar identificar a real percepção sobre a violência obstétrica nos diferentes grupos envolvidos no processo de trabalho de parto, e relatar as experiências desses grupos de acordo com seu entendimento. Compreender esse fenômeno tão complexo torna-se uma ferramenta em prol da humanização do parto.

Percebe-se que a frequência de casos relatados e considerados como violência obstétrica é alta, embora a amostra seja relativamente pequena. Contudo, considera-se que se tal amostra fosse ampliada é provável que esse número de casos seria maior do que o encontrado. 
Vale ressaltar também, que embora o estudo tenha sido realizado com o cuidado de não haver maneiras de influenciar as respostas dos participantes há de se considerar que algumas situações podem levar a uma distorção da resposta dos estudados. Questiona-se, por exemplo, se o fato das gestantes no período pós-parto, ou em outras situações de estresse emocional, responderiam aos questionários de forma diferente do que elas responderiam de uma situação corriqueira. Outra percepção está relacionada com os profissionais da saúde, principalmente alguns atuantes na enfermagem, que em algumas situações questionaram as pesquisadoras sobre uma possível relação do estudo com a instituição no qual eles foram aplicados. Ou seja, questiona-se também, se esses responderam devidamente as indagações, ou se por algum anseio de repercussões negativas com a instituição ou colegas de trabalho tenham desvalorizado suas respostas.

Foi possível estabelecer que o fenômeno da violência na atenção obstétrica é histórico, mas vem ganhando espaço atualmente em virtude de um contexto sociocultural em que a mulher adquire uma posição central. Além disso, a evolução de um sistema médico que visa a fuga do modelo hospitalocêntrico e intervencionista contribui também para essa discussão, e permite a promoção da assistência centrada na pessoa como nova forma de atuação na saúde obstétrica.

A partir disso, obteve-se opiniões pouco divergentes sobre a percepção da violência obstétrica entre os grupos estudados, diferindo de acordo com os aspectos culturais, sociais e econômicos. Contudo, foi concordante o fato de que esse tipo de violência está relacionado, principalmente, com qualquer ato que reflita uma afronta ao direito de escolha da mulher e que priorize práticas que não respeitem a individualidade ou desvalorizem o processo de parturição das mesmas.

Garantir uma reflexão aprofundada sobre as condições da mulher no momento do parto e sobre os atos estabelecidos por todos aqueles envolvidos nessa situação é de extrema importância para auxiliar na desconstrução da violência obstétrica, bem como na valorização da relação médico-paciente. A humanização ainda se estabelece como melhor estratégia para a superação de qualquer problema enfrentado na esfera não só da saúde da mulher, mas também nos direitos dessas perante a sociedade.

\section{REFERÊNCIAS}

ANDRADE, B.P.; AGGIO, C.M. Violência obstétrica: a dor que cala. In: SIMPÓSIO GÊNERO E POLÍTICAS PÚBLICAS,3. [Anais...]. Universidade Estadual de Londrina, 2014.

BOWSER, D.; HILL, K. Exploring evidence for disrespect and abuse in facility-based childbirth: report of a landscape analysis. Bethesda, Maryland: USAID-TRAction Project; 2010.

BRASIL. Ministério da Saúde. Humanização do parto: humanização no pré-natal e nascimento. Distrito Federal, 2002.

CARTILHA Violência Obstétrica - Curitiba. Mandato Goura. Disponível em: https://issuu.com/gouranataraj/docs/cartilha violencia obstetrica ofici .

CIELLO, C. et al. Violência Obstétrica: "Parirás com dor". Dossiê elaborado pela Rede Parto do Princípio para a CPMI da Violência Contra as Mulheres, 2012.

COELHO, E.B.S.; SILVA, A.C.L.G. da; LINDNER, S.R. Violência: definições e tipologias. Florianópolis: UFSC, 2014. 
DINIZ, C.S.G. Entre a técnica e os direitos humanos : possibilidades e limites da humanização da assistência ao parto [tese]. São Paulo (SP): Faculdade de Medicina da Universidade de São Paulo, 2001.

DINIZ, S.G. et al. Violência obstétrica como questão para a saúde pública no Brasil: origens, definições, tipologia, impactos sobre a saúde materna, e propostas para sua prevenção. J. Hum. Growth Dev. v.25, n.3, São Paulo, 2015. DOI: http://dx.doi.org/10.7322/jhgd.106080

GUIMARES, L.B.E.; JONAS, E.; AMARAL, L.R.O.G. Violência obstétrica em maternidades publicas do estado do Tocantins. Revista Estudos Feministas, Florianópolis, v.26, 2017. DOI: http://dx.doi.org/10.1590/180695842018vg6n143278

HOELZ, L; CAMPEO, L. Relação entre síndrome de Burnout, erro médico e longa jornada de trabalho em residentes de medicina. Revista brasileira de medicina do trabalho, v.13, 2015.

KOETTKER, J.G., BRÜGGEMANN, O.M., DUFLOTH, R.M. Planned home births assisted by nurse midwives: maternal and neonatal transfers. Rev Esc Enferm USP [Internet], 2013 Out; [cited 2016 Ago 3]; 47(1):15-21. Available from: http://dx.doi.org/10.1590/S0080-62342013000100002

NARCHI, Nádia Zanon; CRUZ, Elizabete Franco; GONCALVES, Roselane. O papel das obstetrizes e enfermeiras obstetras na promoção da maternidade segura no Brasil.Ciênc. saúde coletiva, Rio de Janeiro, v. 18, n. 4, p. 1059-1068, Apr. 2013 . Available from $<\mathrm{http} / / / \mathrm{www}$. scielo.br/scielo.php?script=sci_arttext\&pid=S141381232013000400019\&lng=en\&nrm=iso>. access on 27 Mar. 2019. http://dx.doi.org/10.1590/S141381232013000400019 .

PEREIRA, J. S. et al. Violência obstétrica: ofensa a dignidade humana. Brazilian Journal of Surgery and Clinical Research, v. 15, p. 103-108, 2016

SAUAIA, A.S.S.; SERRA, M.C.M. Uma dor além do parto: violência obstétrica em foco. Revista de Direitos Humanos e Efetividade. Brasília, v. 2, n. 1, p. 128 - 147. 2016. DOI: http://dx.doi.org/10.26668/IndexLawJournals/2526-0022/2016.v2i1.1076

SENA, Ligia Moreiras; TESSER, Charles Dalcanale. Violência obstétrica no Brasil e o ciberativismo de mulheres mães: relato de duas experiências. Interface (Botucatu), Botucatu , v. 21, n. 60, p. 209-220, mar. 2017 . Disponível em <http://www.scielo.br/scielo.php?script=sci_arttext\&pid=S141432832017000100209\&lng=pt\&nrm=iso>. acessos em 27 mar. 2019. Epub 03-Nov-2016. http://dx.doi.org/10.1590/1807-57622015.0896.

SILVA, L.C.P.; JULIANI, C.M.R.M. A interferência da jornada de trabalho na qualidade do serviço : contribuição a gestão de pessoas. RAS , v. 14, n.54, jan.-mar., 2012.

TESSER, Charles Dalcanale et al. Violência obstétrica e prevenção quaternária: o que é e o que fazer. Revista Brasileira de Medicina de Família e Comunidade, [S.1.], v. 10, n. 35, p. 1-12, jun. 2015. ISSN 2179-7994. Disponível em: 〈https://rbmfc.org.br/rbmfc/article/view/1013〉. Acesso em: 27 mar. 2019. doi:https://doi.org/10.5712/rbmfc10(35)1013.

ZANARDO, Gabriela Lemos de Pinho et al . VIOLÊNCIA OBSTÉTRICA NO BRASIL: UMA REVISÃO NARRATIVA. Psicol. Soc., Belo Horizonte, v. 29, e155043, 2017 . Available from $<$ http://www.scielo.br/scielo.php?script=sci_arttext\&pid=S0102$71822017000100218 \& \operatorname{lng}=e n \& n r m=i s o>$. access on 27 Mar. 2019. Epub July 10, 2017. http://dx.doi.org/10.1590/1807-0310/2017v29155043. 


\section{ANEXO 1}

\section{QUESTIONÁRIO - PACIENTES}

Idade:( )18-25 anos ( )31-40anos
( )26-30 anos
( ) mais que 40 anos

Escolaridade: ( ) Analfabeta

( )Ensino médio

( ) Ensino fundamental ( ) Ensino Superior
Tipo de parto: ( ) Normal
( ) Fórceps
( ) Natural

( ) Cesária ( )Humanizado

Data do parto/atendimento:

Horário do parto/atendimento:

1. Na sua opinião, como foi o atendimento ?

( )muito bom ( )bom ( ) regular ( ) ruim

2. Você acha que faltou alguma coisa?
( ) $\mathrm{Sim}$
( ) Não

Se sim, o quê?

3. $\mathrm{O}$ que você entende ou considera como violência obstétrica?

4. Você já sofreu e/ou presenciou um episódio de violência obstétrica?

$\operatorname{Sim}($ ) Não( )

5. Se na questão anterior você respondeu sim, qual o tipo/episodio de violência obstétrica você sofreu/presenciou?

ANEXO 2

\section{QUESTIONÁRIO (PROFISSIONAIS DA SAÚDE)}

Idade:( )18-25 anos ( )31-40anos

( )26-30 anos ( ) mais que 40 anos

Profissão:( ) Médico(a)

( ) Enfermeiro(a)

( )Técnico de Enfermagem

( ) outro:

1. Como você considera suas condições de trabalho?

( ) muito boa ( ) boa ( ) regular ( )ruim ( ) péssima 
2. Há algum período em que você considera seu rendimento de trabalho prejudicado?

( )manhã ( )tarde ( ) noite ( )plantão/pós plantão ( ) Nenhum

3. O que você entende ou considera como violência obstétrica?

4. Você já presenciou algum caso?

( ) Sim ( )Não

5. Você considera algum procedimento realizado no centro obstétrico como violência obstétrica?
( ) $\operatorname{Sim}$
( )Não

Se sim, cite qual

\section{ANEXO 3}

\section{QUESTIONÁRIO (ESTUDANTES DE MEDICINA)}

Idade:( )18-25 anos ( )31-40anos
( )26-30 anos
( ) mais que 40 anos

Período do curso: ( ) $11^{\circ} / 2^{\circ}$ ano
( ) $3 \% 4^{\circ}$ ano
( ) $5 \% 6^{\circ}$ ano
1. O que você entende ou considera como violência obstétrica?

2. Você já presenciou algum caso?
( ) $\operatorname{Sim}$
( )Não

3. Você considera algum procedimento realizado no centro obstétrico como violência obstétrica?
( ) $\operatorname{Sim}$
( )Não

Se sim, cite qual. 